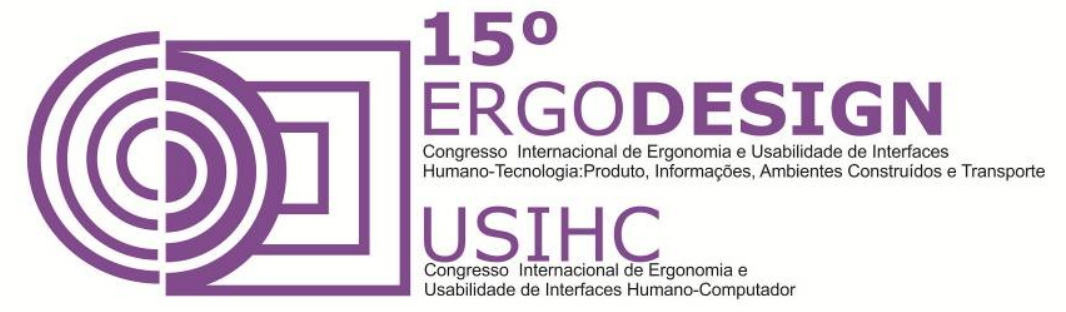

\title{
RECOMENDAÇÕES PARA O DESIGN DE SISTEMAS DE DESENVOLVIMENTO DE DESENHOS TÉCNICOS: ANÁLISE ERGONÔMICA DAS PRANCHETAS PARA DESENHO NAS SALAS DE AULA DO IFBA/ CAMPUS SALVADOR
}

\section{RECOMMENDATIONS FOR DESIGN OF TECHNICAL DRAWINGS OF DEVELOPMENT SYSTEMS: ANALYSIS OF ERGONOMIC DRAWING FOR CLIPBOARDS IN CLASSROOMS OF IFBA / CAMPUS SALVADOR}

\author{
SOARES, Ana Paula dos Anjos Cordeiro (1); \\ MARIÑO, Suzi Maria Carvalho (2); \\ FREITAS, Sydney Fernandes de (3) \\ (1) IFBA/Campus Salvador, Mestre em Artes Visuais (UFBA) \\ e-mail: apacordeiro@gmail.com \\ (2) UNEB/ UFBA, Doutora em Arquitetura e Urbanismo (USP) \\ e-mail: suzimarino@gmail.com
}

(3) UERJ, Doutor em Engenharia de Produção (COPPE/ UFRJ)

e-mail: sydneyfreitas@terra.com.br

\begin{abstract}
RESUMO
Este artigo apresenta recomendações para o design de sistemas de desenvolvimento de desenhos técnicos, resultantes de estudos realizados sobre o uso das pranchetas para desenho pelos estudantes do IFBA. Para tanto, elegeu-se como estratégia metodológica a Intervenção Ergonomizadora. Na Apreciação Ergonômica observou-se que a concentração na execução das tarefas fica comprometida devido o desconforto físico sentido pelos usuários, evidenciado nas entrevistas e registros fotográficos. A Sistematização do SHTM (Sistema Humano-Tarefa-Máquina) apresentou os problemas através de quadros e fluxogramas. Na Diagnose Ergonômica caracterizou-se os problemas de ordem interfacial detectados. Foi realizada a Análise da Tarefa e aplicados questionários e escalas de avaliação. Na conclusao apresentam-se alguns requisitos projetuais.
\end{abstract}

Palavras-chave: Design de Sistemas, Análise Ergonômica, Estação de Trabalho, Desconforto. 


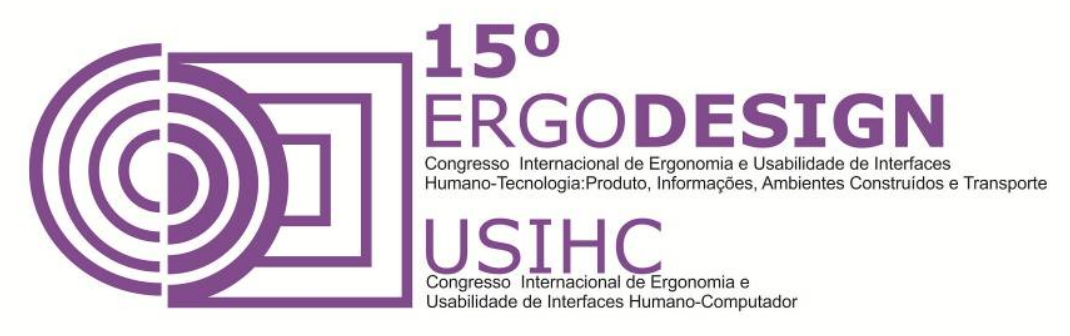

\begin{abstract}
We present recommendations for the design of technical drawings systems development, resulting from studies on the use of clipboards for design by the students of IFBA. For this, he was elected as a methodological strategy Ergonomizadora intervention. In Ergonomic Assessment showed that the concentration in performing the tasks is impaired by physical discomfort felt by users, evidenced in interviews and photographic records. The systematization of SHTM (Human Task-Machine System) presented the problems through tables and flowcharts. In Ergonomic Diagnose characterized the problems of interfacial order detected. Task analysis and questionnaires and rating scales were performed.
\end{abstract}

Keywords: System Design, Ergonomic Analysis, Workstation, Discomfort.

\title{
1. INTRODUÇÃO
}

A finalidade deste trabalho é apresentar recomendações que sirvam de parâmetros para o design de sistemas de desenvolvimento de desenhos técnicos que sejam confortáveis, eficientes e seguros. Tais recomendações são resultantes de estudos realizados sobre o uso das pranchetas para desenho pelos estudantes do Instituto Federal de Educação, Ciência e Tecnologia da Bahia (Campus de Salvador), quando da realização de suas atividades pedagógicas da unidade curricular Desenho na referida estação de trabalho.

A estratégia metodológica adotada para o desenvolvimento da pesquisa foi a metodologia ergonômica conhecida como Intervenção Ergonomizadora, que compreende cinco grandes etapas: a Apreciação Ergonômica, a Diagnose Ergonômica, a Projetação Ergonômica, a Avaliação/ Validação/ Testes Ergonômicos e, por fim, o Detalhamento Ergonômico e Otimização. De acordo com Moraes e Mont'Alvão (2009), uma proposta de Intervenção Ergonomizadora pode compreender apenas a etapa de Apreciação Ergonômica, com uma ou duas etapas seguintes. Na pesquisa em questão foram realizadas as etapas de Apreciação e Diagnose Ergonômica, que consistem na problematização, sistematização e caracterização dos problemas ergonômicos identificados.

A trajetória da pesquisa foi centrada na compreensão do usuário, do produto e da tarefa realizada, como componentes de um sistema, o SHTM (Sistema Humano-Tarefa-Máquina), a fim de obter informações que auxiliem na delimitação e formulação do problema. Para tanto, foram realizadas: a modelagem sistêmica, a análise da tarefa, bem como a aplicação de questionários e escalas de avaliação.

A justificativa se baseia no contexto a seguir explicitado: a expansão da oferta de educação profissional e tecnológica, em todos os seus níveis e modalidades, através da Lei no. 11.892/ 2008; a utilização do equipamento prancheta para desenho, principalmente nas instituições públicas de ensino e nas MPE's; além da realidade atual do IFBA (Campus Salvador): 17 


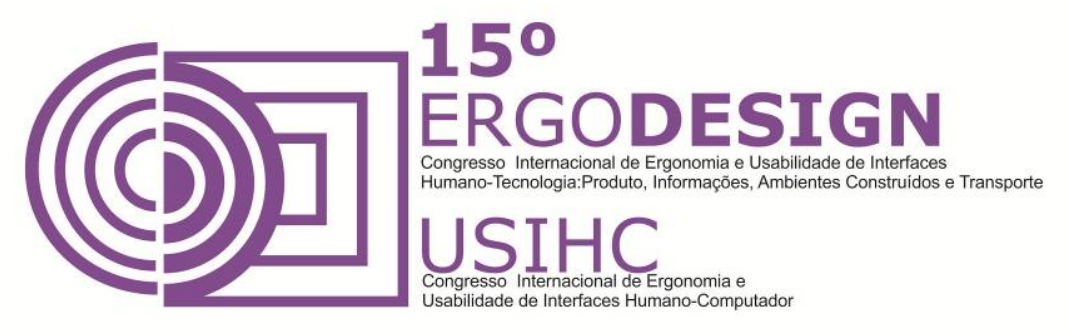

turmas de primeiro ano dos cursos técnicos, 6 turmas de primeiro semestre das engenharias, sem contar: turmas de segundo ano de cursos como Mecânica e Refrigeração, os 4 anos do curso de Edificações e as modalidades Subsequente (Ensino Técnico Profissionalizante para aqueles que já concluíram o Ensino Médio), PROEJA (Programa de Educação de Jovens e Adultos, que oferece cursos de qualificação profissional) e PRONATEC (Programa Nacional de Acesso ao Ensino Técnico criado pelo governo federal, que oferece cursos técnicos profissionalizantes).

\section{PROBLEMA DE PESQUISA}

A prancheta para desenho pode ser definida como um mobiliário destinado ao uso de adolescentes e adultos, cuja finalidade é atender as funções pedagógicas de construção/desenvolvimento, leitura e interpretação de desenhos técnicos, tendo como característica principal a reunião, em uma única estrutura, dos subsistemas assento (banqueta), superfície de trabalho (tampo) e base (pés).

A tarefa de desenvolver desenhos técnicos na prancheta exige de seus executores concentração e destreza. Porém, na maioria das vezes, estes usuários acabam por sacrificar a sua postura e a qualidade de seus trabalhos em função do desconforto que sentem ao utilizar tal equipamento. A postura assumida pela maioria dos estudantes quando da realização de suas atividades nas pranchetas das salas de desenho do IFBA é considerada desconfortável e inadequada, trazendo constrangimentos à coluna vertebral, como pode ser visto na Figura 1 abaixo.
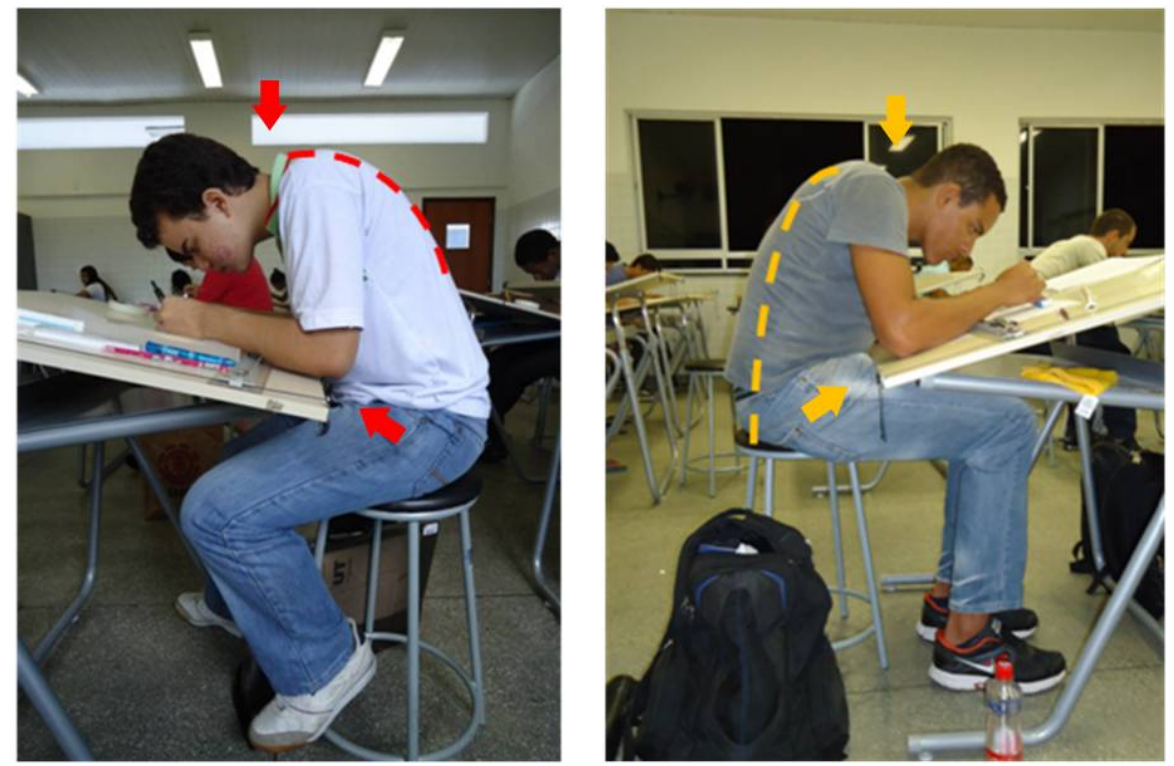

Figura 1 - Estudantes do IFBA/Campus Salvador utilizando a prancheta no desenvolvimento de suas atividades pedagógicas. As linhas tracejadas representam a postura assumida (curvatura da coluna vertebral) e as setas indicam os constrangimentos sofridos na região do pescoço 


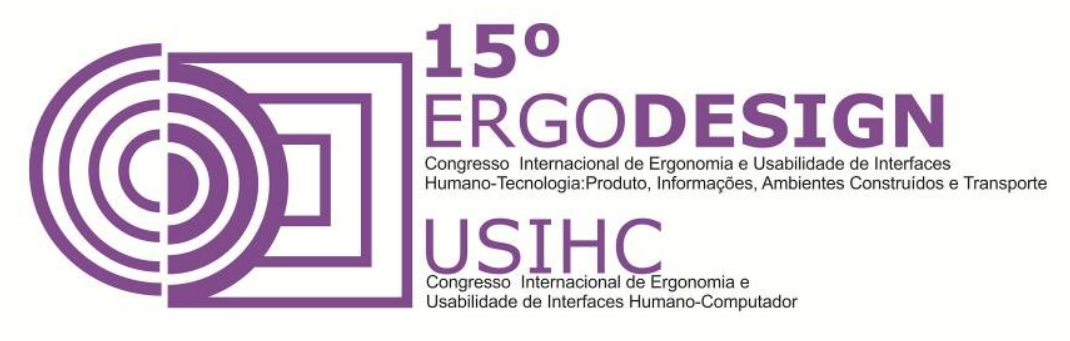

(cervical) e nos membros inferiores (pernas). Fonte: SOARES, 2014.

Moraes e Pequini (2000) afirmam que embora hajam benefícios na postura sentada, como relaxamento dos músculos e diminuição da pressão hidrostática, resultando em uma menor resistência para o retorno do sangue ao coração, a postura sentada também apresenta desvantagens. Os músculos abdominais tendem a se afrouxar, a espinha tende a se curvar e o funcionamento de órgãos internos como os do sistema digestivo e respiratório, torna-se mais difícil.

Aliadas às diferentes características do usuário, como idade, peso, altura, tempo de uso da estação de trabalho e algum tipo de patologia músculo-esquelética, os desconfortos ou constrangimentos decorrentes podem ter uma intensidade ainda maior. Daí a relevância do estudo realizado, cujas questões norteadoras perpassaram por verificar como e em que condições ocorrem o uso das pranchetas para desenho pelos estudantes, quando do desenvolvimento de suas atividades, e por identificar quais são os problemas ergonômicos e custos humanos decorrentes do uso das pranchetas feito por eles, para, então, elaborar recomendações para o design de um novo sistema ou redesign do sistema em questão.

\section{ESTRATÉGIA METODOLÓGICA}

A Ergonomia é uma disciplina científica cuja origem está relacionada com a segunda guerra mundial e é consequência do trabalho interdisciplinar de engenheiros, fisiologistas e psicólogos. Ocupa-se do estudo da interação entre o homem e o trabalho (MORAES \& MONT'ALVÃO, 2009; IIDA, 2005). Esta lança mão dos métodos utilizados pelas ciências sociais, para realizar suas pesquisas e intervenções. E, de acordo com lida (2005), seu enfoque é baseado na teoria de sistemas que advém da biologia: "sistema é um conjunto de elementos (ou subsistemas) que se integram entre si, com um objetivo comum e que evoluem no tempo".

Conforme explicitado na introdução, a Intervenção Ergonomizadora foi a estratégia metodológica adotada para a pesquisa. Foram realizadas as etapas de Apreciação e Diagnose Ergonômica. Na etapa de Apreciação foi realizada a problematização. Foram feitas observações nas salas de aula e entrevistas informais com os estudantes a cerca da utilização da prancheta para a realização das atividades da unidade curricular Desenho. Também foram realizados registros fotográficos que, em muito, auxiliaram na delimitação dos problemas ergonômicos, neste caso, posturais principalmente. A referida etapa culminou com a sistematização do SHTM, que consiste na apresentação ilustrada do problema através da elaboração de quadros, tabelas e fluxogramas conforme demonstrado por Moraes e Mont'Alvão (2009) e realizado por Soares (2014), exemplificado na sessão 4 deste artigo.

A etapa de Diagnose permitiu o aprofundamento e caracterização dos problemas ergonômicos detectados, neste caso, de ordem interfacial principalmente. Foi realizada a análise da tarefa considerando o ambiente físico da sala de aula. Foram aplicados questionários e escalas de avaliação de dor/ desconforto baseada em Corllet e Wilson (1986 apud PEQUINI, 2005) para delinear as atividades e o perfil dos usuários (sessão 5 deste artigo). Identificados os problemas ergonômicos e custos humanos decorrentes da atividade, passa-se à elaboração de 


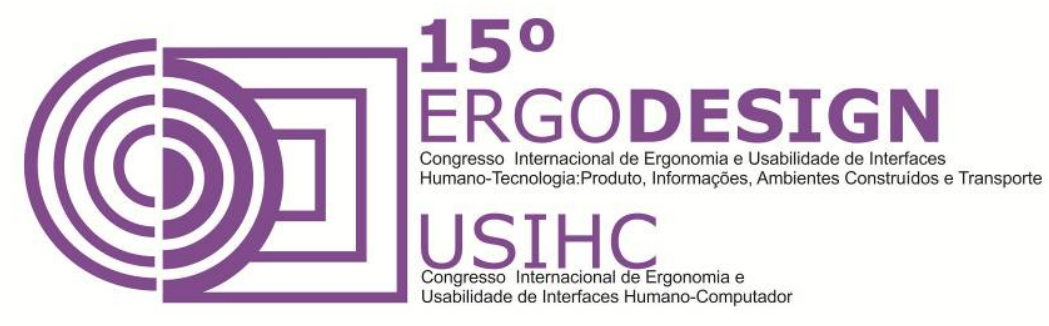

recomendações baseadas em todo o diagnóstico ergonômico, que compreende a confirmação ou a refutação de predições.

A investigação foi realizada por meio de pesquisa bibliográfica e de campo. Para os registros fotográficos foi utilizada uma câmera fotográfica digital da marca Sony, modelo Cyber-shot 14.1 megapixels. Para a aplicação dos questionários e escalas de avaliação, foram estipuladas amostras nos níveis médio e superior, nas modalidades mais representativas do IFBA, o curso técnico integrado e o curso de graduação. Foram definidos, em princípio, 80 estudantes para cada modalidade, em um universo representativo de 6 turmas cada.

\section{APRECIAÇÃO ERGONÔMICA}

Primeira etapa da Intervenção Ergonomizadora, a Apreciação é uma fase exploratória que consiste na sistematização do SHTM e na delimitação dos problemas ergonômicos.

A tarefa de desenvolver desenhos técnicos depende de um sistema organizado que funcione. No caso do IFBA, para que o estudante realize a referida tarefa, se faz necessário o uso do mobiliário que é a prancheta para desenho. Portanto, o sistema de desenvolvimento de desenhos técnicos na prancheta é um Sistema Humano-Tarefa-Máquina.

Foram observados estudantes de cursos técnico e de graduação, atuando no referido sistema para identificação daqueles que vem a ser os problemas ergonômicos relativos ao SHTM em análise. Foram utilizados três modelos do sistema operando: a Caracterização e Posição Serial do Sistema; a Ordenação Hierárquica do Sistema; e, o Fluxograma Funcional Ação-Decisão. À seguir, como exemplo, a Caracterização e Posição Serial do Sistema que compreende a definição dos componentes do sistema em estudo, além de posicioná-los em relação ao sistema-alvo (Figura 2). 

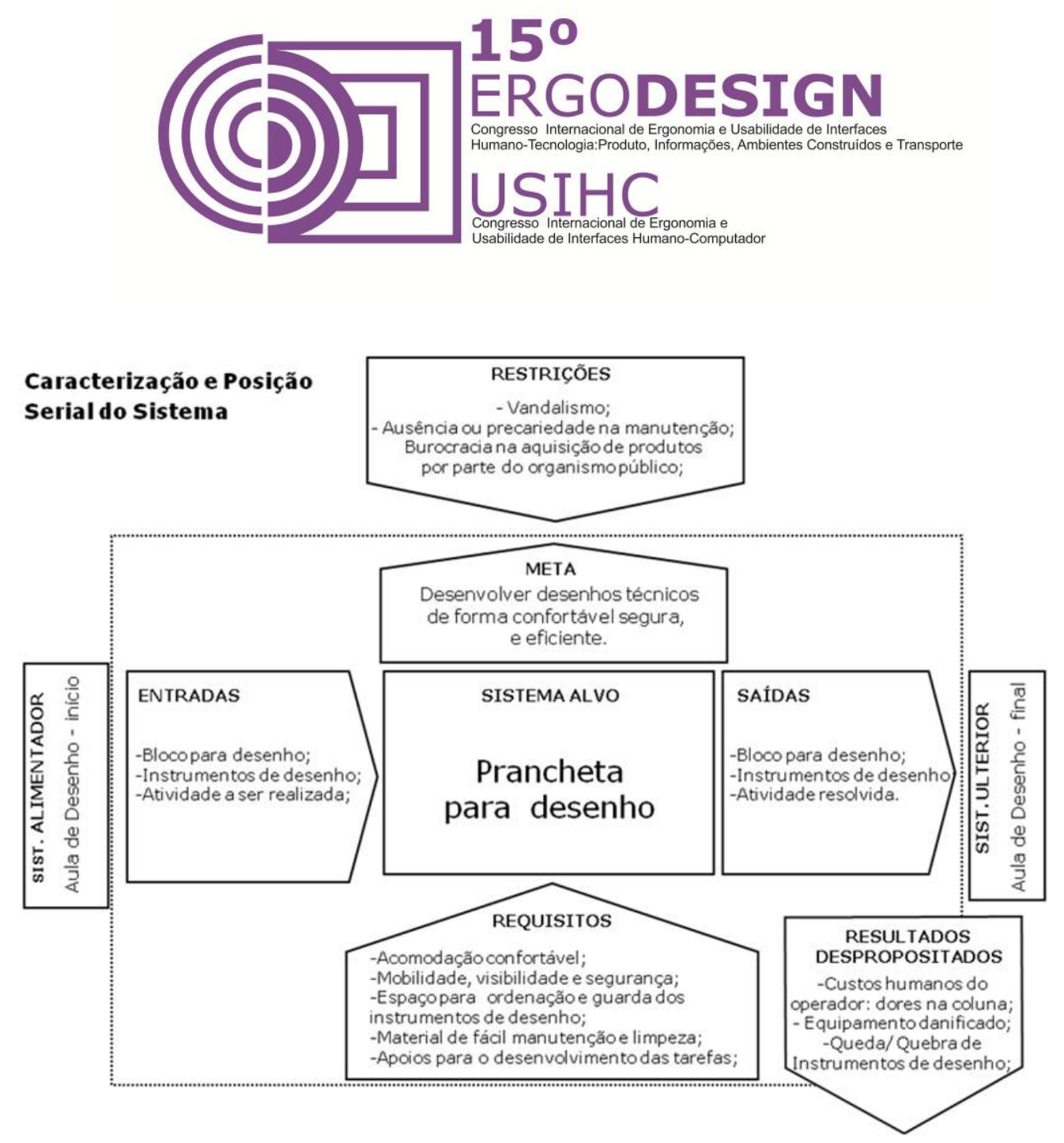

Figura 2 - Caracterização e Posição Serial do Sistema. Fonte: SOARES, 2014 (Adaptado de Moraes e Mont'Alvão, 2009).

A partir desta modelagem compreende-se melhor o funcionamento do sistema e os elementos que o compõem. É possível ainda apontar os resultados despropositados, dentre eles, os custos humanos do operador, que neste caso são as dores na coluna.

De acordo com Kapandji (2000) a coluna vertebral é protetora do eixo nervoso e assim constitui o pilar central do tronco. Daí a sua extrema sensibilidade e cuidado maior quanto ao seu uso. Sua estrutura assemelha-se a um mastro de navio conseguindo integrar os requisitos de firmeza e elasticidade e permitindo, simultaneamente, a sustentação e flexibilidade do tronco.

A Figura 3 apresenta dois exemplos de usuários extremos representantes do percentil 5\%il (menor mulher). Podemos observar que a coluna vertebral parece ser uma das partes do corpo que mais sofre constrangimento. Conforme dito por Moraes e Pequini (2000) e reforçado pelo registro fotográfico realizado, a coluna tende a se curvar causando desconforto no referido usuário.

Ainda na Figura 3, visualizamos mais uma dupla de usuários extremos, agora com maior porte físico. São os representantes do percentil 95\%il (maior homem). Podemos perceber que além do desconforto sentido na região da coluna, apresentam também desconforto nos membros inferiores (pernas e pés). 


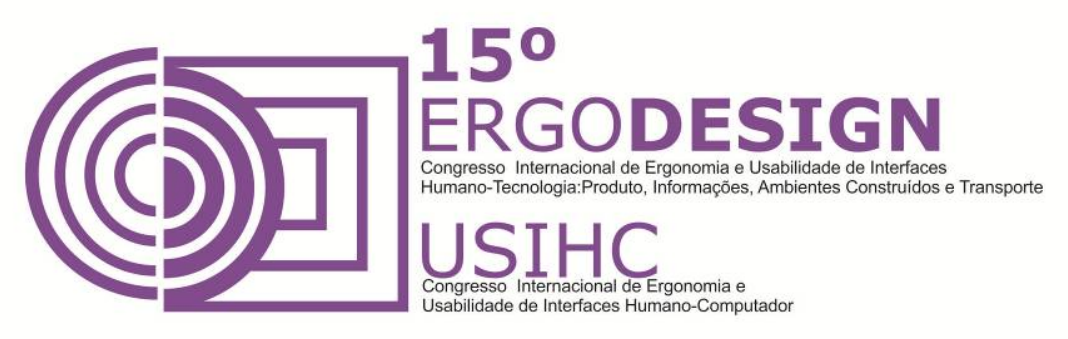

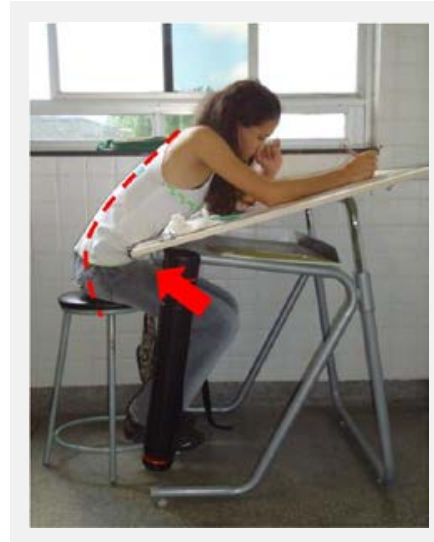

--Percentil 5\%il--

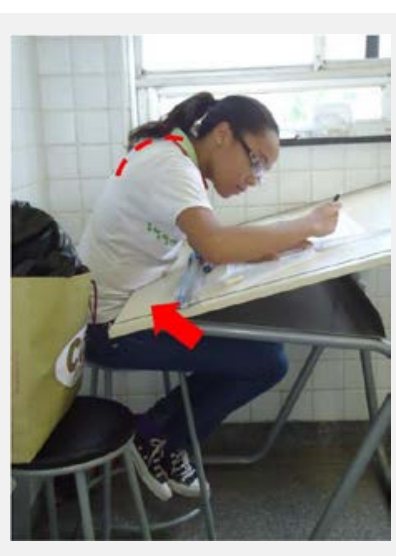

5\%il-
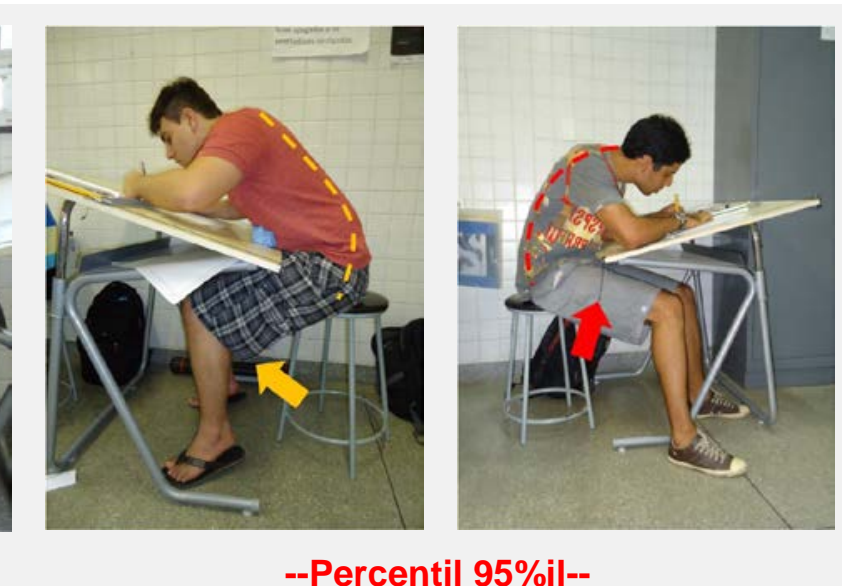

--Percentil 95\%il--

Figura 3 - Estudantes representantes dos percentis 5\%il e 95\%il. As linhas tracejadas representam a postura assumida (curvatura da coluna vertebral) e as setas indicam os constrangimentos sofridos na região do abdominal (no caso dos percentis $5 \%$ il) e nos membros inferiores (pernas - no caso dos percentis 95\%il). Fonte: SOARES, 2014.

A tarefa de desenvolvimento de desenhos técnicos realizada pelos estudantes foi observada de forma assistemática. Os estudantes analisados, durante a execução da tarefa, estão expostos a problemas interfaciais, informacionais e cognitivos. Através da análise da tarefa, verificou-se que durante boa parte do tempo de execução da mesma os estudantes acabam por adotar uma postura inadequada. A tarefa é também dificultada pela ausência de instruções de como regular a prancheta para cada usuário. Além disso, a tensão causada pelo fato do estudante estar desenvolvendo uma atividade acadêmica que, na maioria das vezes, tem um valor atribuído para a verificação do desempenho e aprendizagem técnica do conteúdo influencia.

As atividades implicadas na tarefa, bem como seu ambiente físico e social, exercem sobre o executor certo número de constrangimentos, exigindo-lhe gastos de naturezas diversas: físico, mental, emocional, afetivo, etc., acarretando, portanto, desgastes e custos para o indivíduo, como afirmam Moraes e Mont'Alvão (2009).

Dos problemas observados, foram evidenciados na pesquisa os de ordem interfacial, pois afetam diretamente o bem-estar e podem vir a interferir na saúde dos estudantes, causando dores e lesões irreversíveis.

Na Figura 4 abaixo são enunciados os custos humanos do SHTM em estudo em relação aos problemas ergonômicos interfaciais observados. 

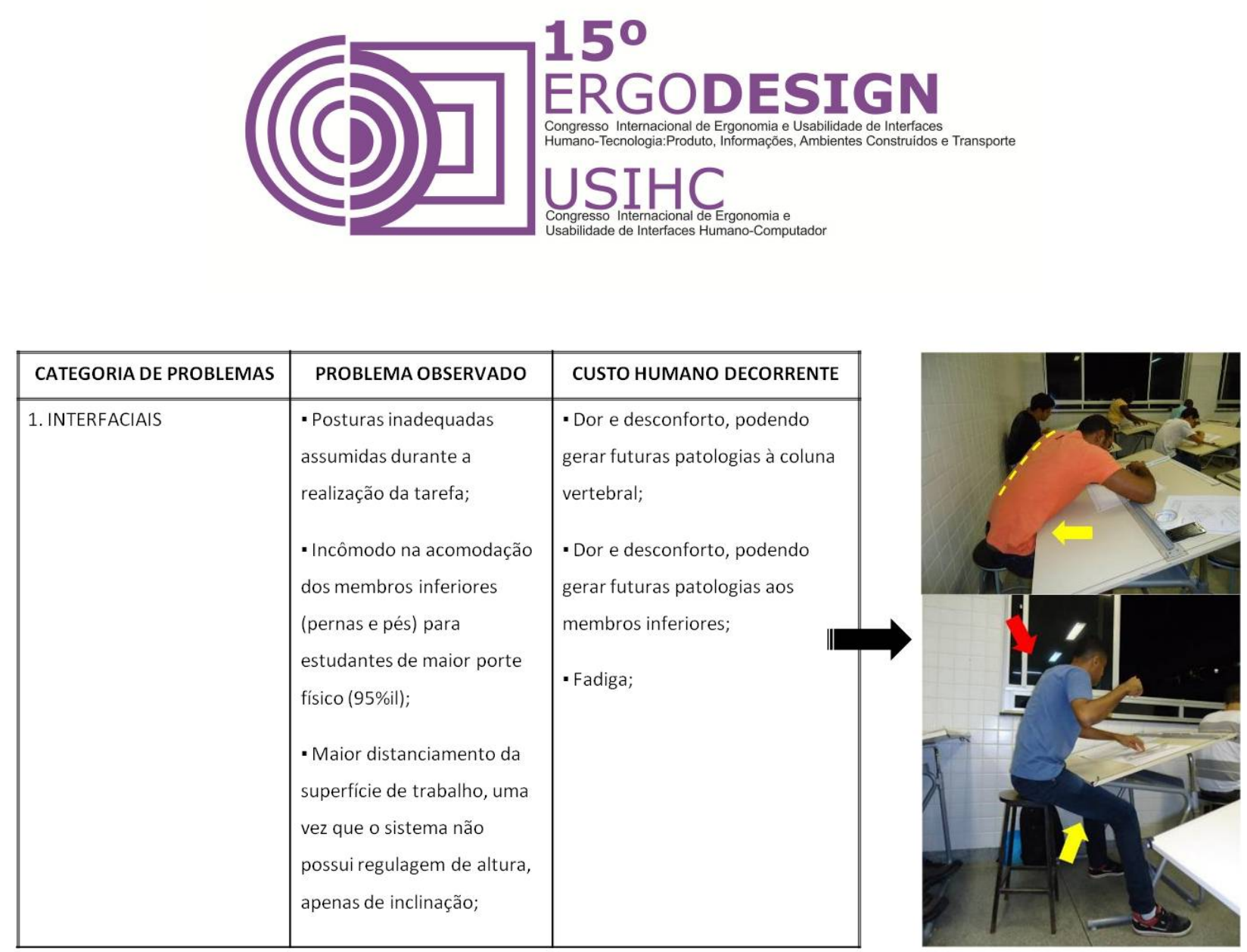

Figura 4 - Problemas ergonômicos x Custos humanos. Fonte: SOARES, 2014.

Os custos humanos bem como a carga cognitiva, psíquica e física do usuário, são gerados pela falta do atendimento aos requisitos ergonômicos que possibilitam maximizar o conforto, a satisfação e o bem-estar, garantir a segurança, minimizar constrangimentos e otimizar o desempenho da tarefa, o rendimento do trabalho e a produtividade do Sistema Humano-TarefaMáquina (PEQUINI, 2007).

\section{DIAGNOSE ERGONÔMICA}

Segunda etapa da Intervenção Ergonomizadora, a Diagnose consiste em aprofundar os problemas priorizados e testar predições. Nesta pesquisa, foram realizadas as seguintes atividades: a análise da tarefa do SHTM em questão e a aplicação de questionários e escalas de avaliação. Foram aplicados os questionários para levantamento do perfil do usuário (Tabela 01) e de avaliação do mobiliário pesquisado, além da escala de avaliação de desconforto corporal baseada em Corllet e Wilson (1986 apud PEQUINI, 2005) 63 estudantes do curso técnico e 48 estudantes do curso de graduação, perfazendo um total de 111 respondentes. $O$ período de aplicação dos questionários e escalas de avaliação se deu entre outubro e dezembro de 2013. 


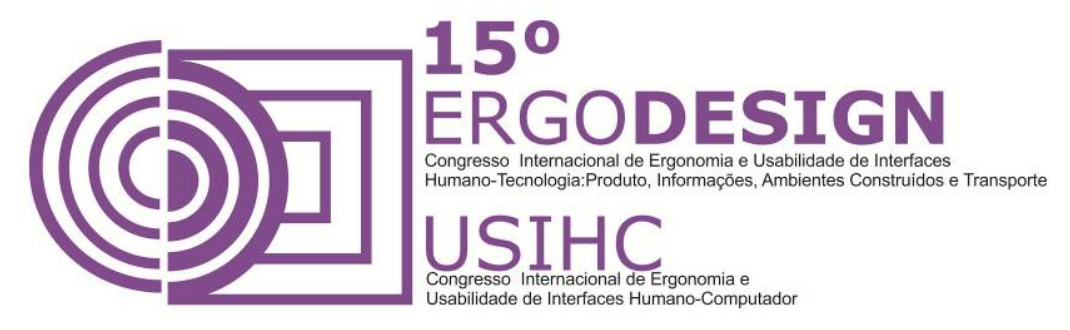

Tabela 01 - Tabela comparativa do perfil do usuário. Fonte: SOARES, 2014.

\begin{tabular}{|c|c|c|}
\hline Perfil do Estudante & Curso Técnico & Graduação \\
\hline 1. Sexo & $\begin{array}{l}\text { Masculino (51\%) } \\
\text { Feminino (49\%) }\end{array}$ & $\begin{array}{l}\text { Masculino }(81 \%) \\
\text { Feminino }(19 \%)\end{array}$ \\
\hline 2. Uso das mãos/ escrita & $\begin{array}{l}\text { Destro (92\%) } \\
\text { Canhoto (5\%) } \\
\text { Ambidestro (3\%) }\end{array}$ & $\begin{array}{l}\text { Destro (92\%) } \\
\text { Canhoto (8\%) } \\
\text { Ambidestro (0\%) }\end{array}$ \\
\hline 3. Idade & $\begin{array}{l}14-19 \text { anos }(100 \%) \\
20-25 \text { anos }(0 \%) \\
26-31 \text { anos }(0 \%) \\
32-37 \text { anos }(0 \%) \\
38-43 \text { anos }(0 \%) \\
44-49 \text { anos }(0 \%) \\
50 \text { anos ou mais }(0 \%)\end{array}$ & $\begin{array}{l}14-19 \text { anos }(25 \%) \\
20-25 \text { anos }(50 \%) \\
26-31 \text { anos }(21 \%) \\
32-37 \text { anos }(4 \%) \\
38-43 \text { anos }(0 \%) \\
44-49 \text { anos }(0 \%) \\
50 \text { anos ou mais }(0 \%)\end{array}$ \\
\hline 4. Peso & $\begin{array}{l}40-54 \mathrm{~kg}(41 \%) \\
55-79 \mathrm{~kg}(49 \%) \\
80-94 \mathrm{~kg}(3 \%) \\
95-109 \mathrm{~kg}(5 \%) \\
110 \mathrm{~kg} \text { ou mais }(2 \%)\end{array}$ & $\begin{array}{l}40-54 \mathrm{~kg}(10 \%) \\
55-79 \mathrm{~kg}(50 \%) \\
80-94 \mathrm{~kg}(38 \%) \\
95-109 \mathrm{~kg}(2 \%) \\
110 \mathrm{~kg} \text { ou mais }(0 \%)\end{array}$ \\
\hline 5. Altura & $\begin{array}{l}1,45-1,55 \mathrm{~m}(5 \%) \\
1,56-1,65 \mathrm{~m}(35 \%) \\
1,66-1,75 \mathrm{~m}(38 \%) \\
1,76-1,85 \mathrm{~m}(17 \%) \\
1,86 \mathrm{~m} \text { ou mais (3\%) }\end{array}$ & $\begin{array}{l}1,45-1,55 \mathrm{~m}(2 \%) \\
1,56-1,65 \mathrm{~m}(5 \%) \\
1,66-1,75 \mathrm{~m}(30 \%) \\
1,76-1,85 \mathrm{~m}(35 \%) \\
1,86 \mathrm{~m} \text { ou mais (3\%) }\end{array}$ \\
\hline 6. Curso & $\begin{array}{l}\text { Química Industrial (48\%) } \\
\text { Eletrotécnica }(51 \%) \\
\text { *Não respondeu }(1 \%)\end{array}$ & $\begin{array}{l}\text { Engenharia Mecânica (60\%) } \\
\text { Engenharia Elétrica }(38 \%) \\
\text { *Não respondeu }(2 \%)\end{array}$ \\
\hline $\begin{array}{l}\text { 7. Tempo de permanência na } \\
\text { prancheta durante a semana }\end{array}$ & $\begin{array}{l}2 \mathrm{~h} / \text { semanais }(100 \%) \\
4 \mathrm{~h} / \text { semanais }(0 \%) \\
\text { Acima de } 4 \mathrm{~h} / \text { semanais }(0 \%)\end{array}$ & $\begin{array}{l}2 \mathrm{~h} / \text { semanais }(2 \%) \\
4 \mathrm{~h} / \text { semanais ( } 94 \%) \\
\text { Acima de } 4 \mathrm{~h} / \text { semanais }(4 \%)\end{array}$ \\
\hline
\end{tabular}

Para que os dados sobre dor/ desconforto corporal fossem obtidos de modo objetivo e apurados de forma sistemática, é que foi utilizado o mapa das regiões corporais de Corllet e Wilson (1986 apud PEQUINI, 2005) (Figura 5). Assim a avaliação da intensidade de desconforto/dor era feita utilizando uma escala que variava de 1 a 5, onde o 1 significava "nenhum" desconforto/dor e o 5 significava "intolerável" desconforto/dor, como pode ser observado na Figura 6: 


\section{(C)]}

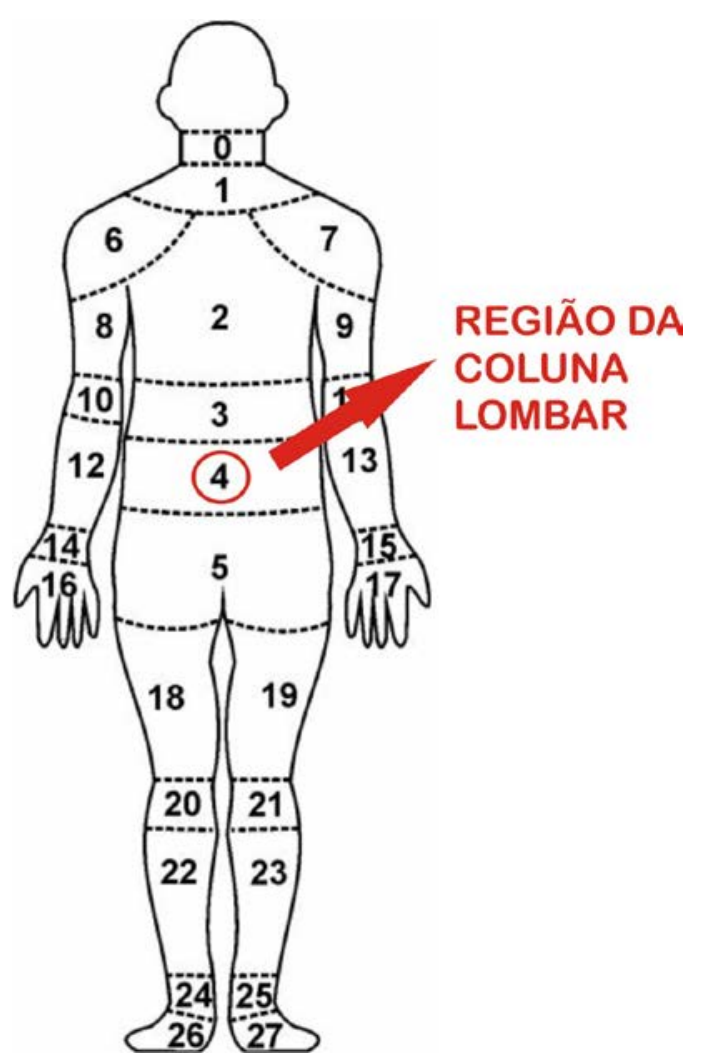

Figura 5 - Mapa das regiões corporais utilizado para avaliação de desconforto/dor. Fonte: Corllet e Wilson (1986 apud PEQUINI, 2005).

\begin{tabular}{|c|c|c|c|c|c|}
\hline $\begin{array}{c}\text { Niveis de } \\
\text { desconforto/dor } \\
\text { Partes do corpo } \\
\end{array}$ & $\begin{array}{c}\text { (1) } \\
\text { Nenhum }\end{array}$ & $\begin{array}{c}\text { (2) } \\
\text { Algum }\end{array}$ & $\begin{array}{c}\text { (3) } \\
\text { Moderado }\end{array}$ & $\begin{array}{c}\text { (4) } \\
\text { Bastante }\end{array}$ & $\begin{array}{c}\text { (5) } \\
\text { Intolerável }\end{array}$ \\
\hline DOPescoço & $18(29 \%)$ & $13(21 \%)$ & $17(27 \%)$ & $10(16 \%)$ & $1(2 \%)$ \\
\hline 01 Cervical & $24(38 \%)$ & $19(30 \%)$ & $12(19 \%)$ & $4(6 \%)$ & \\
\hline 02 Costas-superior & $19(30 \%)$ & $17(27 \%)$ & $10(16 \%)$ & $12(19 \%)$ & \\
\hline 03 Costas-médio & $17(27 \%)$ & $13(21 \%)$ & $14(22 \%)$ & $12(19 \%)$ & $1(2 \%)$ \\
\hline 04 Costas-inferior & $15(24 \%)$ & $14(22 \%)$ & $14(22 \%)$ & $12(19 \%)$ & $3(5 \%)$ \\
\hline 05 Bacia & $41(65 \%)$ & $8(13 \%)$ & $5(8 \%)$ & $4(6 \%)$ & $1(2 \%)$ \\
\hline 06 Ombro esquerdo & $29(46 \%)$ & $18(29 \%)$ & $9(14 \%)$ & $5(8 \%)$ & $1(2 \%)$ \\
\hline 07 Ombro direito & $29(46 \%)$ & $17(27 \%)$ & $11(17 \%)$ & $4(6 \%)$ & $1(2 \%)$ \\
\hline 08 Braço esquerdo & $42(67 \%)$ & $17(27 \%)$ & $3(5 \%)$ & & \\
\hline 09 Braço direito & $41(65 \%)$ & $17(27 \%)$ & $4(6 \%)$ & & \\
\hline 10 Cotovelo esquerdo & $46(73 \%)$ & $10(16 \%)$ & $4(6 \%)$ & $1(2 \%)$ & \\
\hline 11 Cotovelo direito & $47(75 \%)$ & $11(17 \%)$ & $3(5 \%)$ & $1(2 \%)$ & \\
\hline 12 Antebraço esquerdo & $44(70 \%)$ & $11(17 \%)$ & $4(6 \%)$ & $1(2 \%)$ & \\
\hline 13Antebraço direito & $48(76 \%)$ & $9(14 \%)$ & $3(5 \%)$ & $2(3 \%)$ & \\
\hline 14 Punho esquerdo & $39(62 \%)$ & $13(21 \%)$ & $6(10 \%)$ & $3(5 \%)$ & \\
\hline 15 Punho direito & $42(67 \%)$ & $12(19 \%)$ & $6(10 \%)$ & $2(3 \%)$ & \\
\hline $16 \mathrm{M}$ ắ esquerda & $51(81 \%)$ & $8(13 \%)$ & $3(5 \%)$ & & \\
\hline 17 Mão direita & $46(73 \%)$ & $12(19 \%)$ & $2(3 \%)$ & & $2(3 \%)$ \\
\hline 18 Coxa esquerda & $46(73 \%)$ & $11(17 \%)$ & $3(5 \%)$ & $2(3 \%)$ & \\
\hline 19 Coxa direita & $47(75 \%)$ & $9(14 \%)$ & $4(6 \%)$ & $2(3 \%)$ & \\
\hline 20 Joelho esquerdo & $30(48 \%)$ & $20(32 \%)$ & $6(10 \%)$ & $5(8 \%)$ & $1(2 \%)$ \\
\hline 21 Joelho direito & $31(49 \%)$ & $18(29 \%)$ & $7(11 \%)$ & $4(6 \%)$ & $2(3 \%)$ \\
\hline 22 Perna esquerda & $31(49 \%)$ & $19(30 \%)$ & $6(10 \%)$ & $5(8 \%)$ & $1(2 \%)$ \\
\hline 23 Perna direita & $32(51 \%)$ & $17(27 \%)$ & $7(11 \%)$ & $4(6 \%)$ & $2(3 \%)$ \\
\hline 24 Tornozelo esquerdo & $31(49 \%)$ & $19(30 \%)$ & $6(10 \%)$ & $5(8 \%)$ & $1(2 \%)$ \\
\hline 25 Tornozelo direito & $32(51 \%)$ & $17(27 \%)$ & $7(11 \%)$ & $4(6 \%)$ & $2(3 \%)$ \\
\hline 26 Pé esquerdo & $31(49 \%)$ & $19(30 \%)$ & $6(10 \%)$ & $5(8 \%)$ & $1(2 \%)$ \\
\hline 27 Pé direito & $32(51 \%)$ & $17(27 \%)$ & $7(11 \%)$ & $4(6 \%)$ & $2(3 \%)$ \\
\hline
\end{tabular}

Figura 6 - Níveis de dor/desconforto ao final da tarefa (estudantes do curso técnico). Fonte: SOARES, 2014 (Adaptado de PEQUINI, 2005).

Foi constatado que a parte do corpo mais apontada como desconfortável/dolorida pelos estudantes foi a "04 Costas-inferior" que corresponde à região da coluna vertebral conhecida como lombar (vide Figura 5). Isto significa dizer que a coluna lombar é a parte do corpo mais prejudicada e onde os custos humanos (fadiga, dores e lesões) são evidentes. Destacamos também as demais partes do corpo apontadas: regiões da coluna conhecidas como cervical (00 e 01) e dorsal (02 e 03), bacia (05), ombros (06 e 07), mão direita (17), joelhos (20 e 21), além das pernas e pés (22 a 27).

O questionário de avaliação da estação de trabalho constou de duas partes: a primeira coletou a opinião dos usuários sobre os três subsistemas que a compunha: tampo, base e assento, qualificando em "Bom", "Regular" ou "Ruim"; e a segunda tratou das sugestões e colheu a opinião dos estudantes entrevistados em relação a possíveis melhorias. Divididos em sete itens, os usuários puderam opinar utilizando cinco respostas: "É muito importante", "Ajudaria um pouco", "Tanto faz", "Atrapalha mais que ajuda" e "Não sei". 


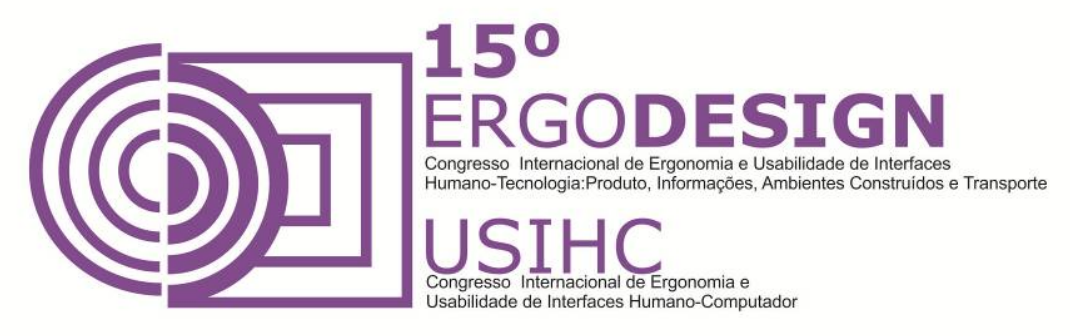

A Tabela 02 abaixo faz uma comparação entre os itens perguntados versus as respostas mais relevantes do questionário de avaliação do mobiliário, parte 2 , intitulado de Sugestões do Usuário para Melhorias:

Tabela 02 - Tabela comparativa de itens perguntados $x$ respostas mais relevantes. Fonte: SOARES, 2014.

\begin{tabular}{|c|c|c|c|c|}
\hline \multirow{2}{*}{$\begin{array}{l}\text { Sugestões do Usuário para } \\
\text { Melhorias (itens x } \\
\text { respostas mais relevantes) }\end{array}$} & \multicolumn{2}{|c|}{ É muito importante } & \multicolumn{2}{|c|}{ Ajudaria um pouco } \\
\hline & Est. C. Técnico & Est. Graduação & Est. C. Técnico & Est. Graduação \\
\hline $\begin{array}{l}\text { 1. Apoio móvel e ajustável } \\
\text { para instrumentos de } \\
\text { desenhos e documentos }\end{array}$ & $84 \%$ & $71 \%$ & $13 \%$ & $25 \%$ \\
\hline $\begin{array}{l}\text { 2. Luminária com } \\
\text { iluminação dirigida para a } \\
\text { área de trabalho }\end{array}$ & $24 \%$ & $33 \%$ & $44 \%$ & $38 \%$ \\
\hline 3. Apoio para o cotovelo & $27 \%$ & $14,5 \%$ & $43 \%$ & $37,5 \%$ \\
\hline 4. Apoio para o punho & $20 \%$ & $13 \%$ & $30 \%$ & $33 \%$ \\
\hline 5. Apoio para os pés & $32 \%$ & $27 \%$ & $35 \%$ & $46 \%$ \\
\hline $\begin{array}{l}\text { 6. Lugar para guardar } \\
\text { objetos pessoais }\end{array}$ & $75 \%$ & $71 \%$ & $21 \%$ & $21 \%$ \\
\hline $\begin{array}{l}\text { 7. Assento com regulagem } \\
\text { de altura }\end{array}$ & $81 \%$ & $92 \%$ & $14 \%$ & $8 \%$ \\
\hline
\end{tabular}

A partir destas informações foi possível constatar o que o público pesquisado considera como essencial e como acessório para a estação de trabalho.

\section{RESULTADOS OBTIDOSI RECOMENDAÇÕES}

Segundo Soares (1990), os fatores fisiológicos e comportamentais dos usuários determinam os requisitos que irão definir o projeto do produto. A utilização da metodologia ergonômica e as informações obtidas através da literatura possibilitam a construção de parâmetros dos quais a indústria pode se apropriar quando da fabricação de novos produtos.

De posse dos conhecimentos construídos sobre o sistema de desenvolvimentos de desenhos técnicos na prancheta e o perfil de seus usuários, apresentamos recomendações que possam servir de parâmetros para o design de novos sistemas ou redesign de produtos existentes para cada subsistema analisado:

\section{- $\underline{\text { Subsistema TAMPO }}$}

- Possibilitar a visualização dos desenhos técnicos, através de um ângulo de visão e altura confortáveis regulados pelo usuário (percentis 2,5\%il a 97,5\%il), de forma a evitar constrangimentos físicos (cervicalgias, dorsalgias, lombalgias e escolioses);

- Possibilitar uma postura sem ocasionar pressão intradiscal por projeção frontal ou lateral do tronco resultando em dor/desconforto e em longo prazo fisiopatologias na coluna vertebral; 


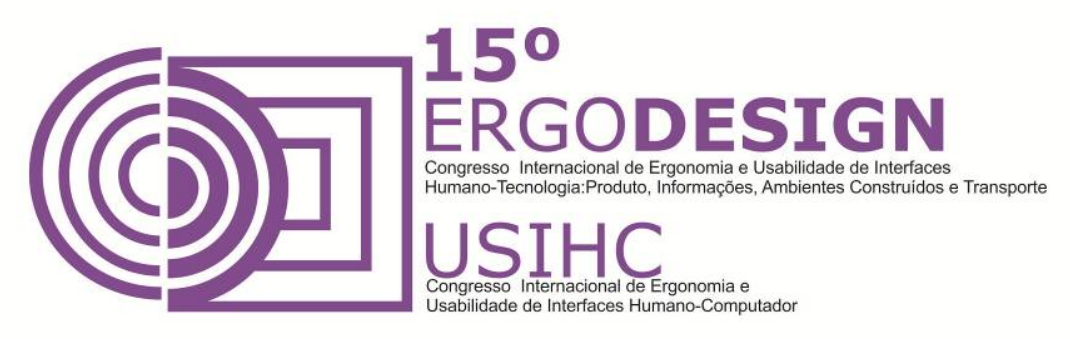

- Possibilitar um conforto biomecânico (ângulos do tronco e dos membros) compatível com a tarefa a ser desempenhada;

- Possuir dimensionamento que permita mobilidade e não dificulte a ação de sentar e levantar da prancheta;

- Prever a colocação de acessórios como: apoio móvel e ajustável (percentis 2,5\%il a 97,5\%il) para instrumentos de desenho e documentos, luminária e apoios para cotovelos e punhos.

\section{- Subsistema BASE}

- Fornecer a sustentação do tampo, além de possibilitar regulagem de altura que atenda aos usuários extremos (2,5\%il a 97,5\% il) e inclinação do mesmo de modo a aproximar o desenho do usuário evitando a projeção frontal do tronco (cervicalgia);

- Disponibilizar espaço para guardar os objetos pessoais dos usuários e apoio para os pés a fim de evitar o aumento da pressão intradiscal que resulta em longo prazo em fisiopatologias irreversíveis para a coluna vertebral.

\section{- Subsistema ASSENTO}

- Fornecer estabilidade corporal satisfatória, através de superfície firme;

- Considerar a adoção de sistemas de regulagem de altura que atenda aos usuários extremos (2,5\%il a 97,5\%il), pois esta é determinante para o conforto nas pernas e na coluna, a manutenção da estabilidade postural e a facilidade de sentar e levantar;

- Adotar acolchoamento em espuma densa, a fim de permitir melhor distribuição do peso do corpo sobre a superfície do assento, diminuindo a pressão das tuberosidades isquiais e bloqueio da circulação sanguínea;

- Dimensionar a superfície do assento em função do maior usuário (97,5\%il).

\section{CONSIDERAÇÕES FINAIS}

A aplicação da metodologia ergonômica na análise e desenvolvimento de produtos propicia o projeto de produtos seguros, confortáveis e eficientes. Seja no trabalho ou na vida cotidiana, valendo-se da contribuição de diversas disciplinas científicas, como, por exemplo, antropometria, psicologia, fisiologia, entre outras, a Ergonomia constitui um conjunto de conhecimentos que resultam no estudo da interação entre o ser humano e o trabalho e, em uma melhor adaptação dos meios tecnológicos e ambientes de trabalho e de vida aos seres humanos.

A atividade de desenvolver produtos exige critério, pesquisa, testes. Deve-se atender aos requisitos tecnológicos, ergonômicos, estéticos e às questões econômicas e de sustentabilidade. Considerada uma atividade científica, procura integrar diversas áreas do conhecimento e estabelecer relações múltiplas para a solução de problemas que envolvem a produção de sistemas de produtos ou serviços, que têm, por objetivo final, atender às necessidades dos seres humanos (NIEMEYER, 2000). 


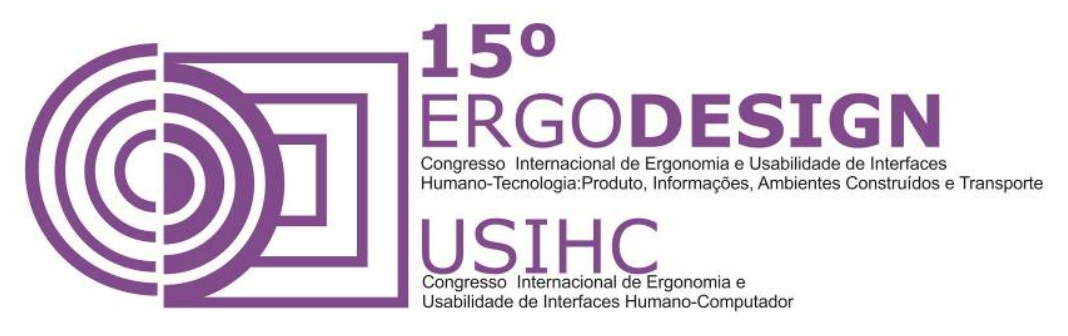

Para desenvolver produtos que atendam aos requisitos ergonômicos, devem-se considerar as características dimensionais (medidas antropométricas) de, no mínimo, 90\% dos usuários, ou seja, de indivíduos cujas dimensões variam entre os percentis 5\%il e 95\%il. Visando garantir maior conforto, podemos estender esta faixa abrangendo do percentil 2,5\%il ao 97,5\%il atendendo, dessa forma, a 95\% dos usuários. Não se deve utilizar a média como referência, pois os resultados certamente serão produtos inadequados dimensionalmente, os quais, em grande parte das vezes, não atendem nem a metade da população à qual se destina o produto.

Conforme descrito neste trabalho, os estudantes assumem as mais diversas posturas quando da realização de suas atividades pedagógicas na estação de trabalho analisada. Em sua maioria, tal postura é considerada inadequada resultando em constrangimentos para a coluna vertebral. De acordo com Soares (1990), o design do espaço de trabalho é determinante para a postura do operador, sendo que uma má postura terá como consequência ineficiência, possibilidade de acidentes e redução na produtividade.

Portanto conclui-se que os conhecimentos construídos sobre o sistema de desenvolvimento de desenhos técnicos na prancheta e o perfil de seus usuários, foram fundamentais para a elaboração de recomendações que sirvam de parâmetros para o design de novos sistemas ou redesign de sistemas de produtos existentes e disponíveis no mercado.

\section{REFERÊNCIAS}

BRASIL. Lei No. 11.892, de 29 de dezembro de 2008. Institui a Rede Federal de Educação Profissional, Científica e Tecnológica e cria os Institutos Federais de Educação, Ciência e Tecnologia. Disponível em: <http://www.planalto.gov.br/ccivil_03/_ato2007-2010/2008/lei/l11892.htm>. Acesso em: outubro de 2013.

IIDA, Itiro. Ergonomia: projeto e produção. São Paulo: Edgar Blucher, 2005. 2ed.

KAPANDJI, A. I. Fisiologia articular: tronco e coluna vertebral. 5 ed. São Paulo: Médica Panamericana, 2000.

MORAES, Anamaria de; MONT'ALVÃO, Cláudia. Ergonomia: conceitos e aplicações. Rio de Janeiro: $2 A B, 2009$.

MORAES, Anamaria de; PEQUINI, Suzi Mariño. Ergodesign para trabalho com terminais informatizados. Rio de Janeiro: $2 A B, 2000$.

NIEMEYER, Lucy. Design no Brasil: origens e instalações. Rio de Janeiro: 2AB, 2000.

PEQUINI, Paolo C. Intervenção Ergonômica e suas implicações na produtividade e satisfação dos funcionários: estudo de caso de lavanderia industrial. Salvador: Faculdade de Tecnologia e Ciências Área 1, 2007. (monografia)

PEQUINI, Suzi M. Ergonomia aplicada ao design de produtos: um estudo de caso sobre o design de bicicletas. São Paulo: USP, 2005. (tese de doutorado)

SOARES, Ana Paula A. Cordeiro. Análise Ergonômica das pranchetas para desenho nas salas de aula do IFBA - Campus Salvador. Salvador: UFBA, 2014. (dissertação de mestrado)

SOARES, Marcelo. Custos humanos na postura sentada e parâmetros para avaliação e projetos de assentos:"Carteira Universitária". Um estudo de caso. Rio de Janeiro: COOPE/UFRJ, 1990. (dissertação) 